\title{
Establishment of immortalized human periodontal ligament cells derived from deciduous teeth
}

\author{
TOMOKAZU HASEGAWA ${ }^{1}$, NAOYUKI CHOSA ${ }^{2}$, TAKEYOSHI ASAKAWA ${ }^{1}$, \\ YOSHITAKA YOSHIMURA $^{3}$, AKIRA ISHISAKI ${ }^{2}$ and MITSURO TANAKA ${ }^{1}$
}

\author{
Departments of ${ }^{1}$ Pediatric Dentistry and ${ }^{2}$ Oral Biochemistry, School of Dentistry, Iwate Medical University, \\ 19-1 Uchimaru, Morioka 020-8505; ${ }^{3}$ Department of Molecular Cell Pharmacology, Division of Oral Pathological Science, \\ Hokkaido University Graduate School of Dental Medicine, Kita 13 Nishi 7, Kita-ku, Sapporo 060-8586, Japan
}

Received May 27, 2010; Accepted July 9, 2010

DOI: $10.3892 /$ ijmm_00000516

\begin{abstract}
Although periodontal ligament (PDL) cells have previously been isolated from permanent teeth, they have not been isolated from deciduous teeth. Here, we used human telomerase reverse transcriptase ( $h T E R T)$ induction to establish the first immortalized PDL cell lines derived from deciduous teeth. Cells were transfected with plasmids containing hTERT. Single-cell cloning was then performed using the limited dilution method. Reverse transcriptase polymerase chain reaction and stretch PCR were used to detect hTERT expression in the clones. In order to determine whether the clones could differentiate into osteoblasts, we stimulated the cells with ascorbic acid and $ß$-glycerophosphate. We successfully obtained 3 single-cell clones, and named them single cell derived from human deciduous PDL (SH) 9, 10 and 11. All the SH cells showed hTERT expression and stable proliferation after $>80$ population doublings and expressed the marker genes of PDL cells, including scleraxis, periostin, cementum-derived protein 23, and tenomodulin. Although all the clones expressed osteoblastic markers, only the clones from the SH 9 cell line differentiated into osteoblastic cells. This is the first report of the immortalization of PDL cells derived from deciduous teeth. These cells could be useful in studies investigating the cellular mechanisms and regenerative processes of human PDL cells.
\end{abstract}

Correspondence to: Dr Tomokazu Hasegawa, Department of Pediatric Dentistry, School of Dentistry, Iwate Medical University, 19-1 Uchimaru, Morioka 020-8505, Japan

E-mail: hasegawa@iwate-med.ac.jp

Abbreviations: hTERT, human telomerase reverse transcriptase; CP-23, human cementum-derived protein-23; TeM, tenomodulin; RUNX2, runt-related transcription factor-2; OSC, osteocalcin; OSN, osteonectin; Col I, type I collagen; ALP, alkaline phosphatase; PTHR, parathyroid hormone receptor

Key words: human periodontal ligament cells, deciduous teeth, human telomerase reverse transcriptase, immortalization, single cell clone, calcification

\section{Introduction}

The periodontal ligament (PDL) is a highly specialized connective tissue that connects the cementum to the alveolar bone (1). PDL tissue consists of a heterogeneous cell population that includes fibroblasts, cementoblasts, osteoblasts, endothelial progenitor cells, epithelial cell rests of Malassez, macrophages, osteoclasts and progenitor/stem cells (2). As PDL is located between the tooth root and alveolar bone, it not only has an important role in supporting the teeth, but also contributes to tooth nutrition, homeostasis and to the repair of damaged tissue (3). However, it is unclear which cells are responsible for homeostasis and the regeneration of PDL tissue.

Fibroblasts are the predominant PDL cell type (4) and are thought to control PDL homeostasis and regeneration (5). Furthermore, we have previously reported that PDL fibroblasts contribute to the regulation of bone metabolism by expressing the receptor activator $\mathrm{NF}-\kappa \mathrm{B}$ ligand and osteoprotegerin $(6,7)$. Fibroblasts derived from the PDL have the ability to form bone-like tissues in vitro, similar to osteoblasts (8), and thus PDL cells function similarly to osteoblasts in hard tissue formation and express proteins with osteoblastic properties such as the runt-related transcription factor-2 (RUNX-2), osterix (9), osteocalcin (OSC) (10), osteonectin (OSN), type I collagen (Col I) (11), alkaline phosphatase (ALP) (12), parathyroid hormone receptor (PTHR) and periostin (13). Other studies have also shown that PDL fibroblasts express scleraxis (14), tenomodulin (15), and the cementum-derived protein-23 (CP-23) (16). However, the mechanism underlying the regulation of the differentiation of PDL cells is unclear.

PDL cells used in previous studies were a heterogeneous population, making it difficult to determine whether the cell types functioned alone or in cooperation with other cell types. These cells had a limited lifespan and were phenotypically unstable (17). Therefore, an immortal PDL cell line is required in order to clarify the functions of individual cells composing PDL.

PDL cell lines have previously been derived from permanent teeth $(18,19)$, but not from deciduous teeth, as the cells are difficult to isolate. Exfoliated deciduous teeth lack their roots, which are needed to isolate the PDL cells, as these are resorbed during the eruption of permanent teeth. As PDL 
cells derived from deciduous teeth are thought to contain more progenitor/stem cells than those derived from permanent teeth, they could be more useful for research.

Most somatic diploid cells lose telomere length during cell replication, leading to replicative senescence (20). Telomere length is dependent upon telomerase, a cellular ribonucleoprotein complex consisting of 2 components, namely integral RNA that serves as the telomeric template, which has reverse transcriptase activity and an associated protein (21). The induction of the human telomerase reverse transcriptase ( $h T E R T)$ results in telomere length elongation and in the extension of the in vitro replicative life span of human mortal somatic cells $(22,23)$.

In this study, we describe how the induction of the hTERT gene allowed us to establish immortalized PDL cells derived from deciduous teeth. We also provide an evaluation of whether these cell lines have PDL properties, and the potential to differentiate into osteoblastic cells in vitro.

\section{Materials and methods}

Cell culture. PDL tissues were obtained from the middle third of the root surfaces of healthy human deciduous teeth, whose roots were not resorbed before the eruption of permanent teeth (obtained from 3 donors, aged 7 to 8 years), as previously described $(6,7)$. Informed consent was obtained from the parents of the donors before tooth extraction, which was carried out in our hospital during the course of orthodontic treatment. The study protocol was approved by the Ethics Committee of Iwate Medical University, School of Dentistry (no. 01101).

A surgical blade was used to cut the PDL tissues into pieces so that they could be digested with collagenase $(2 \mathrm{mg} /$ $\mathrm{ml})$ at $37^{\circ} \mathrm{C}$ for $30 \mathrm{~min}$. The tissues were then washed with Dulbecco's phosphate-buffered saline (PBS), placed on culture dishes, and maintained in $\alpha$-modified minimum essential medium ( $\alpha$-MEM; Gibco BRL, Gaithersburg, MD, USA) supplemented with $10 \%$ foetal bovine serum (FBS; Gibco BRL). Fibroblastic cells that grew from the PDL tissue culture were used as the PDL cells. When they reached confluence in $35-\mathrm{mm}$ culture dishes, they were detached with $0.2 \%$ trypsin and $0.02 \%$ EDTA $4 \mathrm{Na}$ in PBS and subcultured at a 1:4 split ratio. All cultures were maintained at $37^{\circ} \mathrm{C}$ in a humidified atmosphere of $5 \% \mathrm{CO}_{2}$.

Transfection of the hTERT gene. All the PDL cells were transfected with a $p B A B E-n e o-h T E R T$ plasmid containing a neomycin-resistant gene (Addgene plasmid 1774, provided by Addgene Inc. Cambridge, MA, USA) and Lipofectamine ${ }^{\mathrm{TM}}$ LTX (Invitrogen, Carlsbad, CA, USA) according to the manufacturer's instructions. Cells were exposed to $10 \%$ FBS $\alpha$-MEM containing $150 \mu \mathrm{g} / \mathrm{ml} \mathrm{G} 418$ (Gibco BRL) for 12-15 days. The surviving cells were trypsinized and allowed to grow in 100-mm culture dishes.

Single-cell cloning. Single-cell clones were obtained using the limited dilution method. After hTERT transfection and selection with G418, the surviving cells were seeded on a 96-well plate (Corning, NY, USA) at 0.5 cells per well, then incubated at $37^{\circ} \mathrm{C}$ in a humidified incubator in an atmosphere
Table I. Primers used in RT-PCR.

\begin{tabular}{|c|c|c|}
\hline $\begin{array}{l}\text { Gene } \\
\text { name }\end{array}$ & Primer & Oligonucleotide sequence $\left(5^{\prime}-3^{\prime}\right)$ \\
\hline hTERT & $\begin{array}{l}\text { Forward } \\
\text { Reverse }\end{array}$ & $\begin{array}{l}\text { TCTGGGATGCGAACGGGC } \\
\text { TCCGGCTCAGGGGCAGC }\end{array}$ \\
\hline Scleraxis & $\begin{array}{l}\text { Forward } \\
\text { Reverse }\end{array}$ & $\begin{array}{l}\text { TGCGAATCGCTGTCTTTC } \\
\text { GAGAACACCCAGCCCAAA }\end{array}$ \\
\hline Periostin & $\begin{array}{l}\text { Forward } \\
\text { Reverse }\end{array}$ & $\begin{array}{l}\text { TGTTGCCCTGGTTATATGAG } \\
\text { ACTCGGTGCAAAGTAAGTGA }\end{array}$ \\
\hline CP-23 & $\begin{array}{l}\text { Forward } \\
\text { Reverse }\end{array}$ & $\begin{array}{l}\text { AACACATCGGCTGAGAACCTCAC } \\
\text { GGATACCCACCTCTGCCTTGAC }\end{array}$ \\
\hline TeM & $\begin{array}{l}\text { Forward } \\
\text { Reverse }\end{array}$ & $\begin{array}{l}\text { TTGAAGACCCACGAAGTAGA } \\
\text { ATGACATGGAGCACACTTTC }\end{array}$ \\
\hline RUNX2 & $\begin{array}{l}\text { Forward } \\
\text { Reverse }\end{array}$ & $\begin{array}{l}\text { CCCCACGACAACCGCACCAT } \\
\text { GTCCACTCCGGCCCACAAATC }\end{array}$ \\
\hline Osterix & $\begin{array}{l}\text { Forward } \\
\text { Reverse }\end{array}$ & $\begin{array}{l}\text { CCTGGCTGCGGCAAGGTGT } \\
\text { GATCTCCAGCAAGTTGCTCTGC }\end{array}$ \\
\hline OSC & $\begin{array}{l}\text { Forward } \\
\text { Reverse }\end{array}$ & $\begin{array}{l}\text { CAGCAAAGGTGCAGCCTTTGT } \\
\text { TCCTGAAAGCCGATGTGGTC }\end{array}$ \\
\hline OSN & $\begin{array}{l}\text { Forward } \\
\text { Reverse }\end{array}$ & $\begin{array}{l}\text { CCGAAGAGGAGGTGGTGGCGG } \\
\text { ACGGGGTGGTCTCCTGCCTCC }\end{array}$ \\
\hline Col I & $\begin{array}{l}\text { Forward } \\
\text { Reverse }\end{array}$ & $\begin{array}{l}\text { ACTGGGGAAACCTGTATCCGG } \\
\text { AAGGGCAGGCGTGATGGCTTA }\end{array}$ \\
\hline ALP & $\begin{array}{l}\text { Forward } \\
\text { Reverse }\end{array}$ & $\begin{array}{l}\text { CTCGTTGACACCTGGAAGAGC } \\
\text { ACAGGATGGCAGTGAAGGGCT }\end{array}$ \\
\hline PTHR & $\begin{array}{l}\text { Forward } \\
\text { Reverse }\end{array}$ & $\begin{array}{l}\text { AGGAACAGATCTTCCTGCTGCA } \\
\text { TGCATGTGGATGTAGTTGCGCGT }\end{array}$ \\
\hline$\beta$-actin & $\begin{array}{l}\text { Forward } \\
\text { Reverse }\end{array}$ & $\begin{array}{l}\text { CTGGCACCACACCTTCTACAATG } \\
\text { AATGTCACGCACGATTTCCCGC }\end{array}$ \\
\hline
\end{tabular}

of $95 \%$ air and $5 \% \mathrm{CO}_{2}$. After the cells had grown for 10 days, they were treated with trypsin and subcultured into 24-well plates (Corning). This was repeated until confluency was reached at 20 days after single cell cloning. The population doubling (PD) level was defined as the number of doublings required for a single cell to reach confluence in a $100-\mathrm{mm}$ culture dish. Both the PDs and the incubation day were considered to be zero when single-cell cloning was performed. PD was estimated at 20 for the PDL cell clones. Clones obtained after single-cell cloning in this study were named single cell derived from human deciduous PDL (SH).

Telomeric repeat amplification protocols. Telomerase activity was assayed by the stretch PCR method, using the TeloChaser (Toyobo, Osaka, Japan), according to the manufacturer's instructions. The TAG-U primer was mixed with crude cell extracts from SH or HeLa cells $\left(2.5 \times 10^{4}\right.$ cells for each reaction) and was incubated at $37^{\circ} \mathrm{C}$ for $60 \mathrm{~min}$ to produce telomeric repeats (TTAGGG). After the telomerase reaction, DNA was purified and amplified with CTA-R primers. The PCR products were separated on a $10 \%$ acrylamide SDS-PAGE gel and stained with ethidium bromide. A HeLa cell extract was used as the positive control for telomerase activity. Heat-treated $\left(60^{\circ} \mathrm{C}\right.$ for $\left.10 \mathrm{~min}\right)$ extracts of HeLa cells served as the negative control. 
A

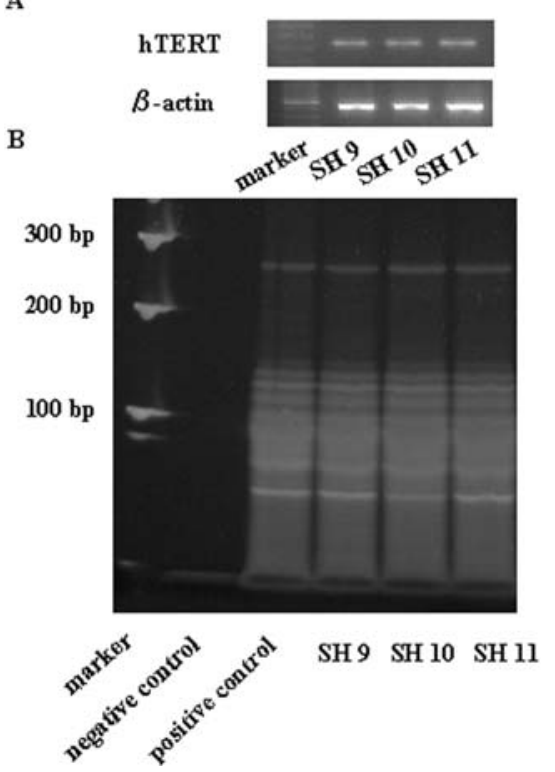

Figure 1. Expression of hTERT mRNA and hTERT activity in SH cells. (A) Telomerase activity was detected using stretch-PCR methods. (B) HeLa cells were used as the positive control. HeLa cells extract inactivated by heat treatment was used as the negative control.

Gene expression detection with reverse transcription polymerase chain reaction ( $R T-P C R)$. After 23 PDs, total RNA from the $\mathrm{SH}$ clones was isolated using TRIzol reagent (Invitrogen), according to the manufacturer's instructions. RNA sample $(1 \mu \mathrm{g})$ was reverse-transcribed to first-strand cDNA using a PrimeScript RT reagent kit (Takara Shuzo, Kyoto, Japan), according to the manufacturer's instructions. mRNA from cDNA samples was amplified with specific

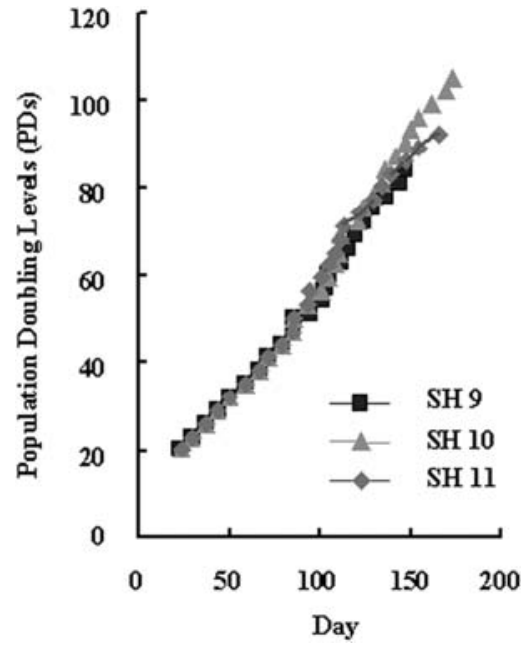

Figure 2. PD levels of SH cells.

primer pairs for B-actin, hTERT (19), scleraxis (15), periostin (24), CP-23 (16), and tenomodulin (TeM) (15) for the PDL markers, and RUNX2 (25), osterix (19), OSC, OSN, Col1a, ALP, and PTHR (26) for the osteoblastic cell markers. The primer sequences are shown in Table I.

Calcification assay. All the SH clones were cultured on 60-mm culture dishes with or without $10 \%$ FBS $\alpha$-MEM containing $50 \mu \mathrm{g} / \mathrm{ml}$ ascorbic acid (Nakarai Tesque, Kyoto, Japan) and 6 mM ß-glycerophosphate (Sigma, St. Louis, MO, USA), a mixture referred to here as the differentiation medium (DM). Half the medium in each dish was exchanged every 2-3 days. After 4 weeks of culture, the cells were fixed with $10 \%$

A

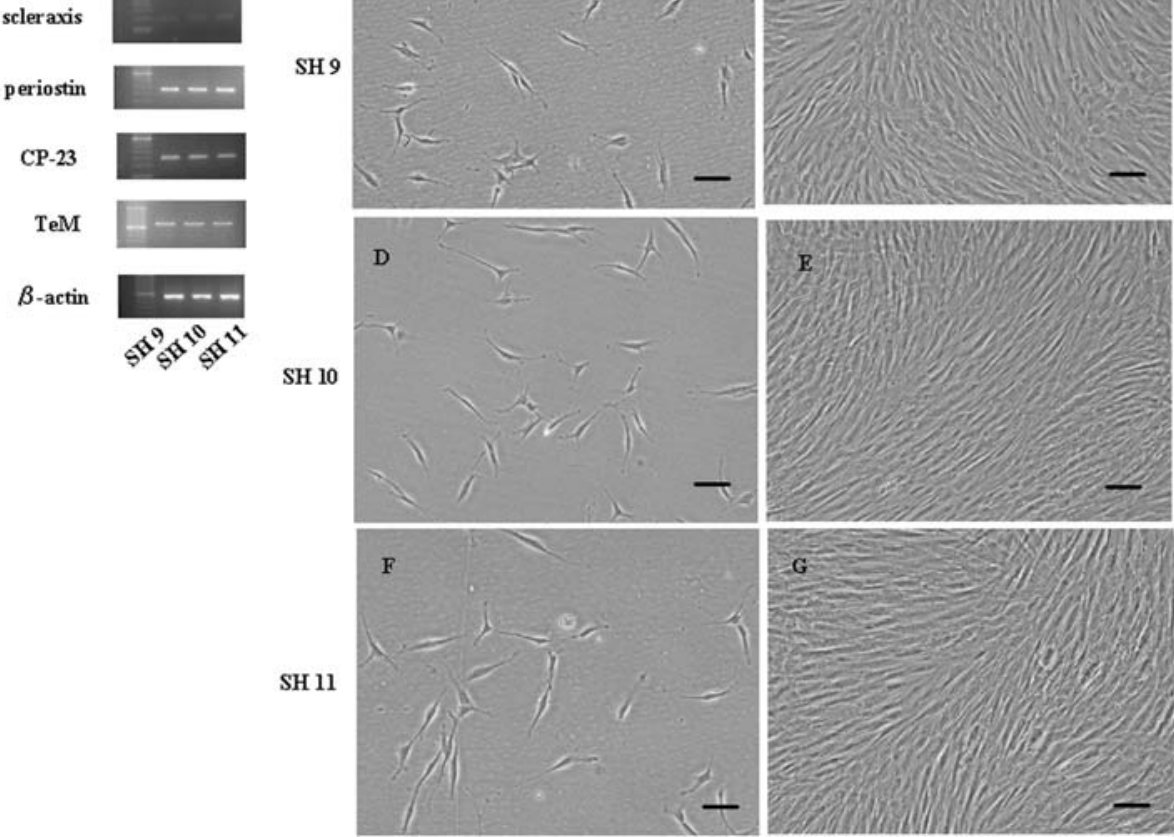

Figure 3. Results from RT-PCR analysis and comparison of SH cell morphology. (A) All the SH cell lines expressed mRNAs specific for PDL at 23 PDs. (B) There was no difference in the morphologies of the SH cell clones, either before or after confluence. The bars represent $100 \mu \mathrm{m}$. 
A

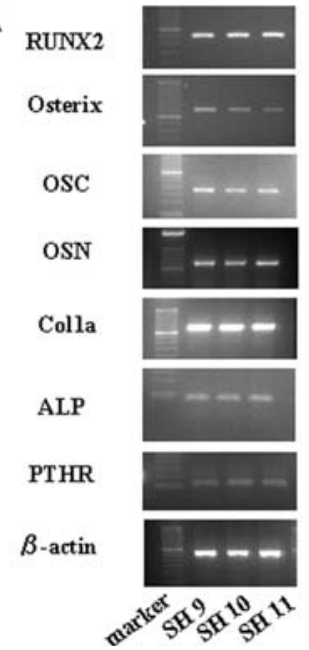

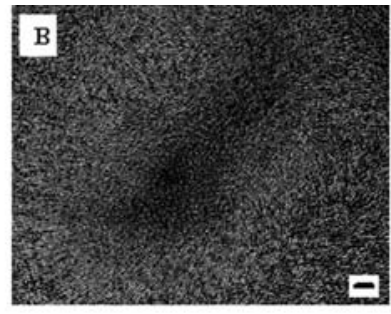
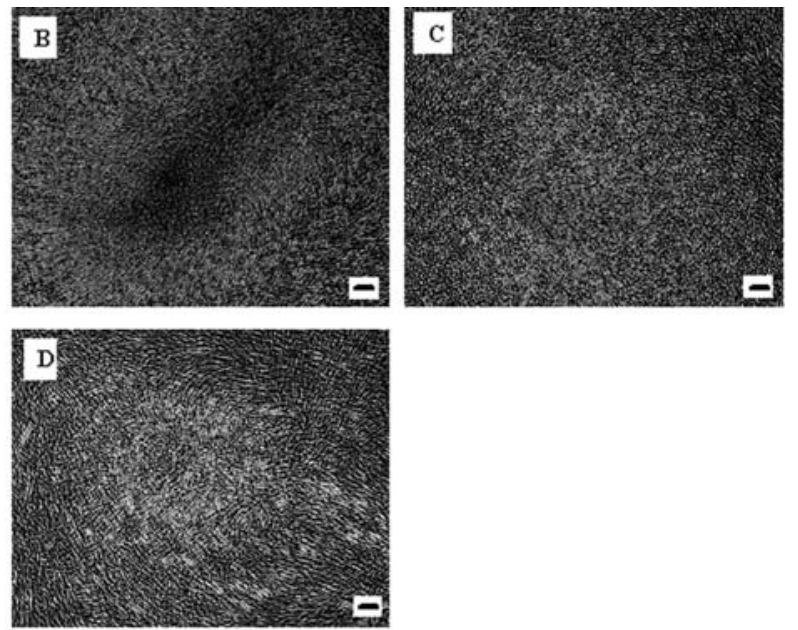

Figure 4. RT-PCR analysis and von Kossa staining in the SH cells cultured in DM for 4 weeks. (A) mRNA expression of RUNX2, osterix, OSC, OSN, Col I, ALP and PTHR in SH cells. Results of von Kossa staining using phase-contrast microscopy. The SH 9 cells formed mineralized nodules (B) though the SH 10 and 11 cells only formed multilayered nodules $(\mathrm{C}$ and $\mathrm{D})$. The bars represent $100 \mu \mathrm{m}$.

formaldehyde, then washed with distilled water and exposed to von Kossa stain, as previously described (27).

\section{Results}

Expression of hTERT in SH cell lines 9, 10, and 11. At PD 23, we observed the hTERT mRNA expression in the SH cell lines 9, 10 and 11 (Fig. 1A). The stretch PCR method indicated that there was telomerase activity in the SH extracts and the positive control, but not in the negative control (Fig. 1B). These results show that the $\mathrm{SH}$ cell line possesses telomerase activity.

Growth curve of SH cell lines 9, 10 and 11. All SH cell lines grew at a similar rate, $\sim 1 \mathrm{PD}$ every 2 days (Fig. 2). The SH cells divided at least 80 times and were passaged $>40$ times.

Characteristics of SH cell lines 9, 10, and 11. At PD 23, all the SH cells expressed scleraxis, periostin, $\mathrm{CP}-23$, and TeM (Fig. 3A), at levels similar to those of the original primary PDL cells. However, the scleraxis expression was lower than that of the other genes.

The cells in all the 3 lines were spindle-shaped (Fig. 3B, $\mathrm{D}$ and $\mathrm{F}$ ), a feature consistent with fibroblasts. After culture confluence, there were no morphological differences among the SH clones (Fig. 3C, E and G).

Osteogenic characterization. At PD 23, all the SH cell lines expressed bone-related genes, such as RUNX2, osterix, OSC, OSN, Col I, ALP and PTHR (Fig. 4A).

The SH 9 cells cultured in DM formed von Kossa-positive calcified deposits (Fig. 4B). The SH 10 and 11 cells cultured in DM formed multilayer nodules, but not calcified deposits (Fig. 4C and D).

\section{Discussion}

In this study, we established 3 PDL fibroblast cell lines immortalized by transfection with $h T E R T$. SH 9 cells have the characteristics of original primary cells with respect to morphological appearance, gene expression, and production of calcified deposits. Our results suggest that immortalized cells such as these could be useful tools for elucidating the biology and regenerative mechanisms of human PDL.

Normal cells have a limited capacity to divide, and cellular senescence occurs immediately in vitro. This is thought to result from telomere DNA loss with passage progression (28). Since cellular senescence is induced by telomere shortening in certain cell types, the overexpression of the hTERT gene, which prevents this process, facilitates the immortalization of cells $(21,23)$. In the SH cell lines transfected with the hTERT gene (lines 9-11), we observed telomerase activity and growth that was not retarded over $>80$ PDs. The morphology of the SH cell lines was not altered. These results suggest that the $h T E R T$ gene was stably expressed. Additionally, the induction of the hTERT gene extended cell lifespan by preventing cellular senescence.

PDL cells have osteoblastic properties and the capacity to form bone-like tissue in vitro (8). In this study, only the SH 9 cells incubated in DM produced calcified deposits. However, the SH 10 and 11 cells also expressed RUNX2, osterix, OSC, OSN, Col I, ALP and PTHR, despite having no osteogenic ability (Fig. 4A). SH 10 and 11 formed multilayered nodules when cultured in DM, but did not produce calcified deposits (Fig. 4C and D). Based on these findings, we believe that we successfully isolated both osteogenic and non-osteogenic cell lines from the original PDL cells.

All the SH cell lines expressed scleraxis and TeM mRNA. Scleraxis, a basic helix-loop-helix transcription factor, is expressed in tendon progenitor populations and mature tendons $(14,29)$. TeM is a late marker of tendon formation $(30,31)$. PDLs have tendon-like features, and they usually do not differentiate into osteoblasts and form bone. This could be a mechanism used to maintain PDL space in vivo. Additionally, periostin is an extracellular matrix protein that is expressed in PDL and periosteum (32). CP-23 is expressed in PDL fibroblasts and cementoblasts but not in osteoblasts (16). Altogether, the presence of these products in our $\mathrm{SH}$ 
cell lines indicates that the isolated cells have properties expected of PDL fibroblasts.

It has previously been reported that PDL cells from permanent teeth could not be immortalized with the hTERT gene alone (19). In this study, PDL cells from deciduous teeth were immortalized with single transfection of the $h T E R T$ gene. As we also failed to establish immortalized cells from dental pulp and PDL isolated from permanent teeth with the hTERT gene alone (data not shown), it has been suggested that certain systems such as tumor-suppression, could differ between deciduous and permanent teeth.

To our knowledge, this is the first study detailing how immortalized PDL cells can successfully be derived from deciduous teeth. We achieved this in 3 separate cell lines by transfecting them with the hTERT gene in order to elongate the telomeres. These immortalized cells could be useful tools for understanding the cellular functions and maintenance of PDL tissues. They could also be useful in regenerative therapies for periodontitis and oral injuries.

\section{Acknowledgements}

This study was supported in part by Grants-in-Aid for Scientific Research (no. 18592026 to A.I., no. 19791370 to N.C. and no. 18592239 to T.H.) from the Ministry of Education, Culture, Sports, Science and Technology of Japan, the Open Research and High-Tech Research Project from the Ministry of Education, Culture, Sports, Science and Technology of Japan, the Akiyama Foundation (to T.H., 2005), as well as a grant from the Keiryokai Research Foundation (no.100 to N.C., 2008 and no.106 to T.H., 2009).

\section{References}

1. Carnes DL, Maeder CL and Graves DT: Cells with osteoblastic phenotypes can be explanted from human gingival and periodontal ligament. J Periodontol 68: 701-707, 1997.

2. Freeman E: Oral histology: Development, structure, and function. In: Periodontium. Ten Cate AR (ed). 5th edition. Mosby, St. Louis, pp253-288, 1998

3. Bartold PM, McCulloch CA, Narayanan AS and Pitaru S: Tissue engineering: a new paradigm for periodontal regeneration based on molecular and cell biology. Periodontol 2000 24: 253-269, 2000.

4. Beertsen W, McCulloch CA and Sodek J: The periodontal ligament: a unique, multifunctional connective tissue. Periodontol 2000 13: 20-40, 1997.

5. Lekic P and McCulloch CA: Periodontal ligament cell populations: the central role of fibroblasts in creating a unique tissue. Anat Rec 245: 327-341, 1996.

6. Hasegawa T, Yoshimura Y, Kikuiri T, Yawaka Y, Takeyama S, Matsumoto A, Oguchi $\mathrm{H}$ and Shirakawa T: Expression of receptor activator of NF-kappa B ligand and osteoprotegerin in culture of human periodontal ligament cells. J Periodontal Res 37: 405-411, 2002.

7. Hasegawa T, Kikuiri T, Takeyama S, Yoshimura Y, Mitome M, Oguchi $\mathrm{H}$ and Shirakawa T: Human periodontal ligament cells derived from deciduous teeth induce osteoclastogenesis in vitro. Tissue Cell 34: 44-51, 2002.

8. Basdra EK and Komposch G: Osteoblast-like properties of human periodontal ligament cells: an in vitro analysis. Eur J Orthod 19: 615-621, 1997.

9. Kato C, Kojima T, Komaki M, Mimori K, Duarte WR, Takenaga $\mathrm{K}$ and Ishikawa I: S100A4 inhibition by RNAi upregulates genes in periodontal ligament cells. Biochem Biophys Res Commun 326: 147-153, 2005.

10. Li H, Bartold PM, Young WG, Xiao Y and Waters MJ: Growth hormone induces bone morphogenetic proteins and bone-related proteins in the developing rat periodontium. J Bone Miner Res 16: 1068-1076, 2001.
11. Lukinmaa PL and Waltimo J: Immunohistochemical localization of types I, V and VI collagen in human permanent teeth and periodontal ligament. J Dent Res 71: 391-397, 1992.

12. Yamashita Y, Sato M and Noguchi T: Alkaline phosphatase in the periodontal ligament of the rabbit and macaque monkey. Arch Oral Biol 32: 677-678, 1987.

13. Yamada S, Murakami S, Matoba R, Ozawa Y, Yokokoji T, Nakahira Y, Ikezawa K, Takayama S, Matsubara K and Okada H: Expression profile of active genes in human periodontal ligament and isolation of PLAP-1, a novel SLRP family gene. Gene 275: 279-286, 2001.

14. Seo BM, Miura M, Gronthos S, Bartold PM, Batouli S, Brahim J, Young M, Robey PG, Wang CY and Shi S: Investigation of multipotent postnatal stem cells from human periodontal ligament. Lancet 364: 149-155, 2004.

15. Itaya T, Kagami H, Okada K, Yamawaki A, Narita Y, Inoue, M, Sumita Y and Ueda M: Characteristic changes of periodontal ligament-derived cells during passage. J Periodontal Res 44: 425-433, 2009.

16. Alvarez-Perez MA, Narayanan S, Zeichner-David M, Carmona BR and Arzate H: Molecular cloning, expression and immunolocalization of a novel human cementum-derived (CP-23). Bone 38: 409-419, 2006.

17. Adams AM, Soames JV and Searle RF: Cultural and morphological characteristics of human periodontal ligament cells in vitro. Arch Oral Biol 38: 657-662, 1993.

18. Fujita T, Otsuka-Tanaka Y, Tahara H, Ide T, Abiko Y and Mega J: Establishment of immortalized clonal cells derived from periodontal ligament cells by induction of the hTERT gene. J Oral Sci 47: 177-184, 2005.

19. Fujii S, Maeda H, Wada N, Kano Y and Akamine A: Establishing and characterizing human periodontal ligament fibroblasts immortalized by SV40T-antigen and hTERT gene transfer. Cell Tissue Res 324: 117-125, 2006.

20. Campisi J: Cellular senescence as a tumor-suppressor mechanism. Trend Cell Biol 11: 527-531, 2001.

21. Shay JW, Zou Y, Hiyama E and Wright WE: Telomerase and cancer. Hum Mol Genet 10: 677-685, 2001.

22. Counter CM, Hahn WC, Wei W, Caddle SD, Beijersbergen RL, Lansdorp PM, Sedivy JM and Weinberg RA: Dissociation among in vitro telomerase activity, telomere maintenance, and cellular immortalization. Proc Natl Acad Sci USA 95: 14723-14728, 1998.

23. Shay JW, Lichtsteiner S and Wright WE: Extension of life-span by introduction of telomerase into normal human cells. Science 279: 349-352, 1998.

24. Kanno A, Satoh K, Masamune A, Hirota M, Kimura K, Umino J, Hamada S, Satoh A, Egawa S, Motoi F, Unno M and Shimosegawa T: Periostin, secreted from stromal cells, has biphasic effect on cell migration and correlates with the epithelial to mesenchymal transition of human pancreatic cancer cells. Int J Cancer 122: 2707-2718, 2008.

25. Ogawa E, Maruyama M, Kagoshima H, Inuzuka M, Lu J, Satake M, Shigesada K and Ito Y: PEBP2/ PEA2 represents a family of transcription factors homologous to products of the Drosophila runt gene and human AML I gene. Proc Natl Acad Sci USA 90: 6859-6863, 1993.

26. Chosa N, Taira M, Saitoh S, Sato N and Araki Y: Characterization of apatite formed on alkaline-heat-treated Ti. J Dent Res 83: 465-469, 2004

27. Maeda H, Wada N, Fujii S and Akamine A: Fibroblastic cells from periapical granulation tissue preferentially form calcified matrices in decalcified and boiled rat bone. Cell Tissue Res 320: 135-140, 2005.

28. Blackburn EH: The molecular structure of centromeres and telomeres. Annu Rev Biochem 53: 163-194, 1984.

29. Brent AE, Schweizer R and Tabin CJ: A somatic compartment of tendon progenitors. Cell 113: 235-248, 2003.

30. Docheva D, Hunziker EB, Fassler R and Brandau O: Tenomodulin is necessary for tenocyte proliferation and tendon maturation. Mol Cell Biol 25: 699-705, 2005.

31. Shukunami C, Takimoto A, Oro M and Hiraki Y: Scleraxis positively regulates the expression of tenomodulin, a differentiation marker of tenocytes. Dev Biol 298: 234-247, 2006.

32. Horiuchi K, Amizuka N, Takeshita S, Takamatsu H, Katsuura M, Ozawa H, Toyama Y, Bonewald LF and Kudo A: Identification and characterization of a novel protein, periostin, with restricted expression to periosteum and periodontal ligament and increased expression by transforming growth factor beta. J Bone Miner Res 14: 1239-1249, 1999. 